\author{
Abstracta Iranica \\ Abstracta Iranica Revue bibliographique pour le domaine irano-aryen \\ Volume 37-38-39 | 2018 \\ Comptes rendus des publications de 2014-2016
}

\title{
Pierfrancesco Callieri. “The Bust-Pillar: a new type of monument in ancient Iran?"
}

\section{Rémy Boucharlat}

\section{(2) OpenEdition}

\section{Journals}

Édition électronique

URL : http://journals.openedition.org/abstractairanica/47202

DOI : 10.4000/abstractairanica.47202

ISBN : 1961-960X

ISSN : 1961-960X

Éditeur :

CNRS (UMR 7528 Mondes iraniens et indiens), Éditions de l'IFRI

Référence électronique

Rémy Boucharlat, «Pierfrancesco Callieri. "The Bust-Pillar: a new type of monument in ancient Iran ?" », Abstracta Iranica [En ligne], Volume 37-38-39 | 2018, document 75, mis en ligne le 30 décembre 2018, consulté le 02 octobre 2020. URL : http://journals.openedition.org/abstractairanica/47202 ; DOI : https://doi.org/10.4000/abstractairanica.47202

Ce document a été généré automatiquement le 2 octobre 2020.

Tous droits réservés 


\title{
Pierfrancesco Callieri. "The Bust- Pillar: a new type of monument in ancient Iran?"
}

\author{
Rémy Boucharlat
}

\section{RÉFÉRENCE}

Pierfrancesco Callieri. "The Bust-Pillar: a new type of monument in ancient Iran ?" in Christian Cannuyer (ed.). Entre Orient et Occident. Circulation des hommes, porosité des héritages. Rika Gyselen in honorem. Bruxelles : Société Belge d'Etudes Orientales, 2016, p. 17-28. (Acta Orientalia Belgica, 29)

1 Le dossier des bustes sassanides en stuc, deux à Hajiabad dans le Fars, douze à Kish en Mésopotamie ou les exemplaires uniques en pierre de même époque ou d'époque parthe à Hamadan, Malyan, Tang-i Bot, Paikuli, n'avait pas été abordé dans son ensemble depuis les découvertes des dernières décennies. L'analyse fine de l'A en particulier sur la partie inférieure creuse, qui indique qu'ils étaient fixés sur un support avec tenon, permet de réfuter l'hypothèse qui eut cours longtemps de bustes fixés sur un mur. Comme l'indique les exemples de Hajiabad, trouvés à proximité de bases de demi- colonnes engagées imitant le type achéménide, ces têtes ou bustes formaient la partie supérieure de ces colonnes (bust pillar), et dans certains cas de têtes en ronde bosse, surmontaient peut-être d'autres éléments architecturaux, mais non des statues. 


\section{AUTEURS}

\section{RÉMY BOUCHARLAT}

UMR 5133 CNRS-Université de Lyon 